\title{
Synthesis and Quantum Mechanical Studies of a Highly Stable Ferrocene- incorporated Expanded Porphyrin
}

Tamal Chatterjee, ${ }^{1}$ G. G. Theophall, ${ }^{2}$ K. Ishara Silva, ${ }^{2}$ K. V. Lakshmi ${ }^{2, *}$ and Mangalampalli

\author{
Ravikanth, ${ }^{1, *}$ \\ ${ }^{\mathbf{1}}$ Department of Chemistry \\ Indian Institute of Technology \\ Bombay, Mumbai 400 076, India \\ E-mail: ravikanth@chem.iitb.ac.in \\ ${ }^{2}$ Department of Chemistry and Chemical Biology and \\ The Baruch '60 Center for Biochemical Solar Energy Research \\ Rensselaer Polytechnic Institute \\ Troy, NY 12180 \\ E-mail: lakshk@rpi.edu
}

\section{Table of Contents}

1. HR-MS mass spectrum of compound 4 ....................................... 1

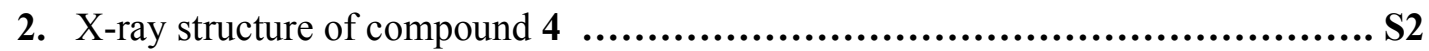

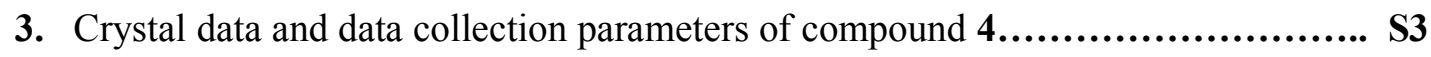

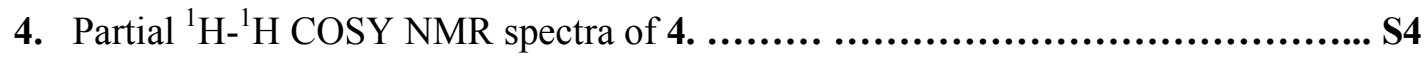

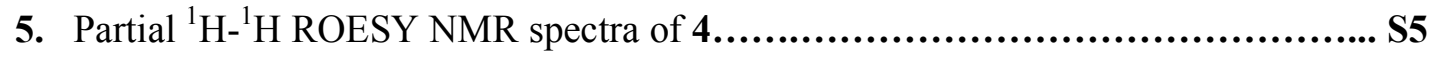

6. Partial ${ }^{1} \mathrm{H}-{ }^{1} \mathrm{H}$ COSY NMR spectra of $4.2 \mathbf{H}^{2+}$..................................... S6

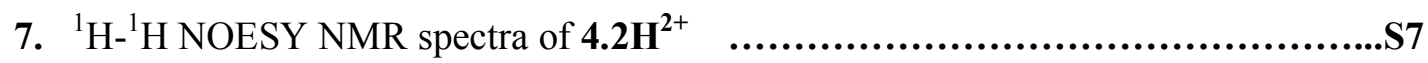

8. ${ }^{1} \mathrm{H}$ NMR comparison of $\mathbf{4 . 2 \mathbf { H } ^ { 2 + }}$ recorded at variable temperature......................S8

9. ${ }^{1} \mathrm{H}$ NMR titration of $\mathbf{4}$ with TFA...................................................S9

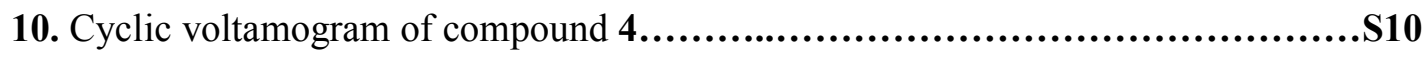

11. Dihedral angles between the heterocycles of compound $4 \quad \ldots . \ldots \ldots \ldots \ldots \ldots \ldots \ldots \ldots . . . . .511$

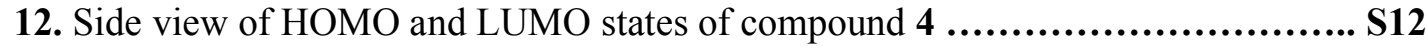

13. Dihedral angles of the meso substituent groups of compound $4 \ldots \ldots \ldots \ldots \ldots \ldots$ S13

14. Side view of HOMO and LUMO states of compound $4.2 \mathbf{H}^{2+}$....................... S14

15. Dihedral angles of the meso substituent groups of compound $4.2 \mathbf{H}^{2+} \ldots \ldots \ldots \ldots . . . . . .515$ 


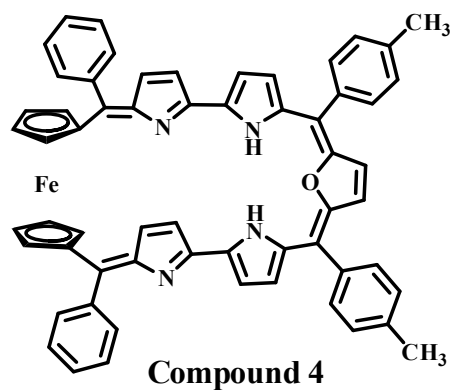

Mol. Wt. $=892.1454$

Peak at $[M+1]^{+}=893.1361$

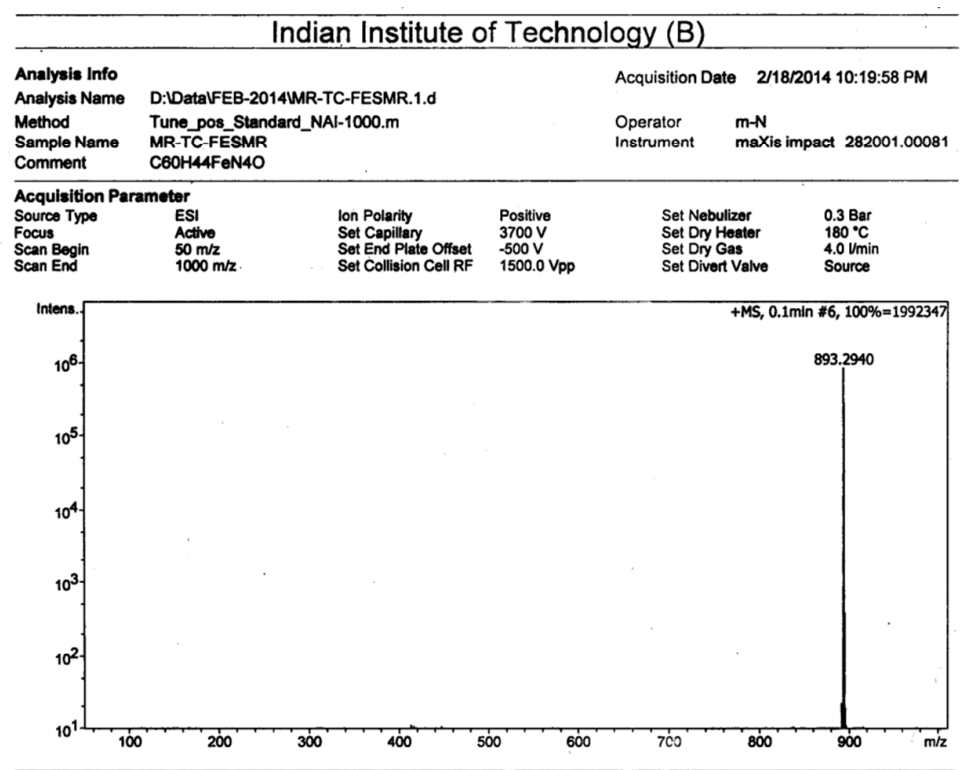

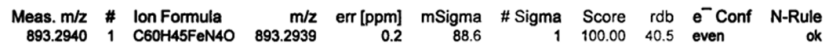

Figure S1. The HR-MS spectrum of compound 4. 


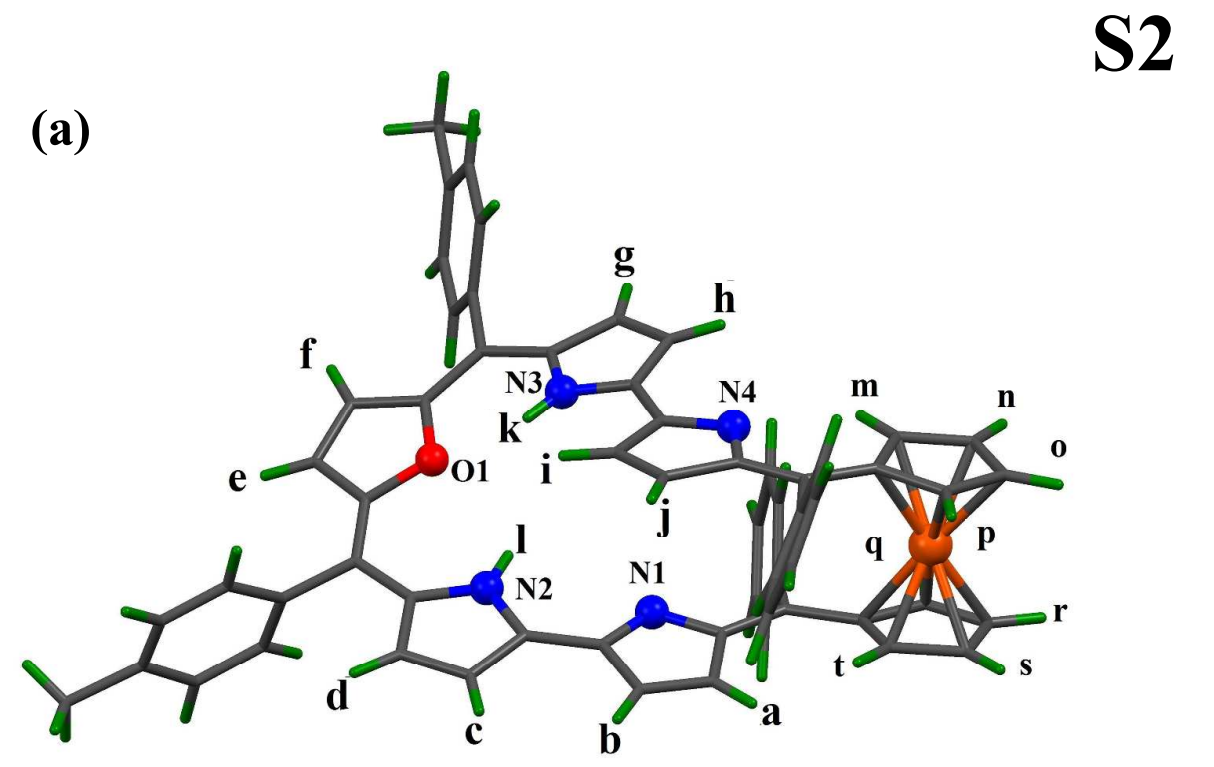

(b)

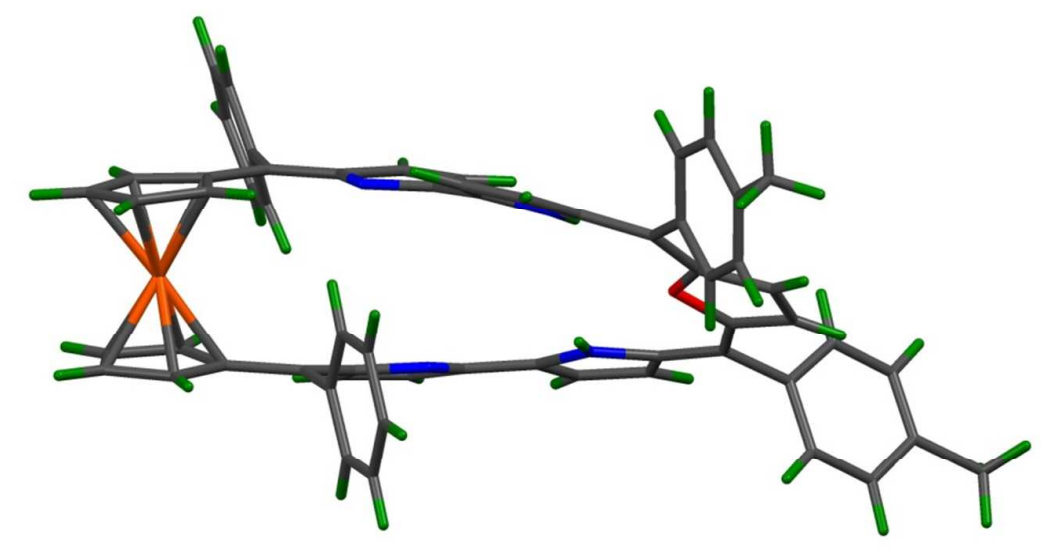

Figure S2: (a) The perspective view of compound $\mathbf{4}$ and (b) the side view representing the partially-twisted structure of the compound 4 . 
Table S1: Crystal data and data collection parameters of compound 4.

\begin{tabular}{|c|c|}
\hline Parameters & $\mathbf{4}$ \\
\hline mol formula & $\mathrm{C}_{60} \mathrm{H}_{46} \mathrm{FeN}_{4} \mathrm{O}_{2}$ \\
CCDC No. & 1404474 \\
formula weight & 908.84 \\
crystal system & Orthorhombic \\
space group & $P b c n$ \\
Temp (K) & 200 \\
$\mathrm{a}(\AA)$ & $27.222(15)$ \\
$\mathrm{b}(\AA)$ & $14.681(7)$ \\
$\mathrm{c}(\AA)$ & $25.452(12)$ \\
$\alpha\left(^{\circ}\right)$ & 90 \\
$\beta\left(^{\circ}\right)$ & 90 \\
$\gamma\left(^{\circ}\right)$ & 90 \\
$\mathrm{~V}\left(\AA^{3}\right)$ & $10172(9)$ \\
$\mathrm{Z}$ & 8 \\
$\mu\left(\mathrm{mm}^{-1}\right)$ & 0.342 \\
$\mathrm{~d}_{\text {calcd }}\left(\mathrm{g} \mathrm{cm}^{-3}\right)$ & 1.187 \\
$\mathrm{~F}(000)$ & 3792 \\
$2 \theta$ range $\left({ }^{\circ}\right)$ & $2.4-25.1$ \\
Independent reflection & 9050 \\
$\mathrm{R} 1, \mathrm{WR} 2[\mathrm{I}>2 \sigma(I)]$ & $0.110,0.2451$ \\
$\mathrm{R} 1, \mathrm{WR} 2\left(^{\circ}\right.$ all data $)$ & $0.288,0.3257$ \\
$\mathrm{GOF}$ & 1.02 \\
Largest diff. peak/hole, $\left(\mathrm{e} / \AA^{\wedge}{ }^{3}\right)$ & $0.93,-0.52$ \\
& \\
\hline
\end{tabular}




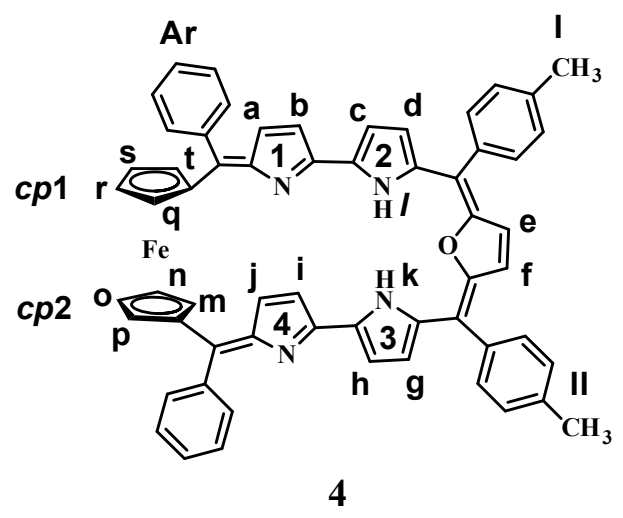

S4

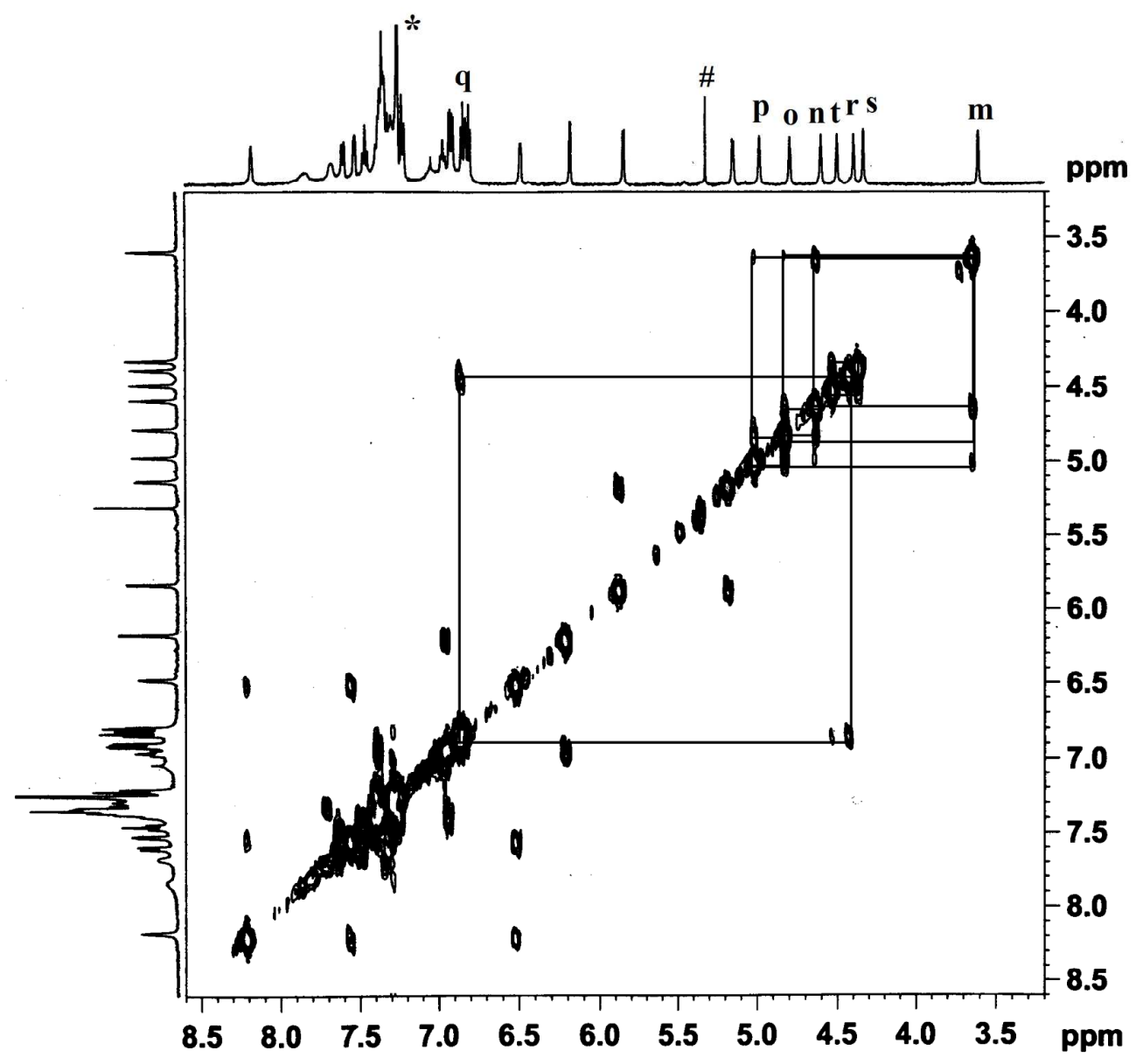

Figure S3: The partial ${ }^{1} \mathrm{H}-{ }^{1} \mathrm{H}$ COSY NMR spectra of compound 4 with the cross-peak connectivity between cyclopentadienyl protons (cp1 \& cp2 rings), recorded in $\mathrm{CDCl}_{3}$ at - 40 ${ }^{\circ} \mathrm{C}(233 \mathrm{~K})$ (* and \# denote peaks from the residual solvent protons). 


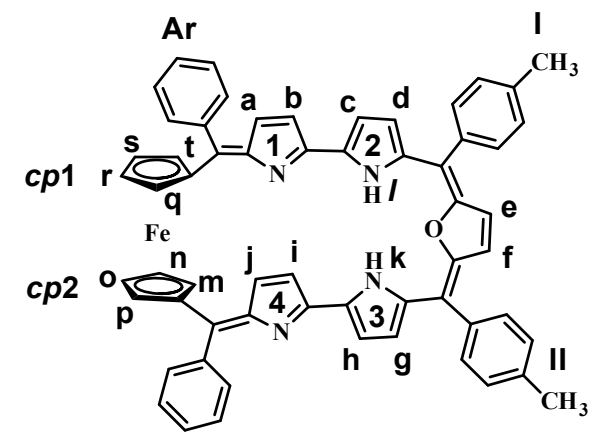

S5

4

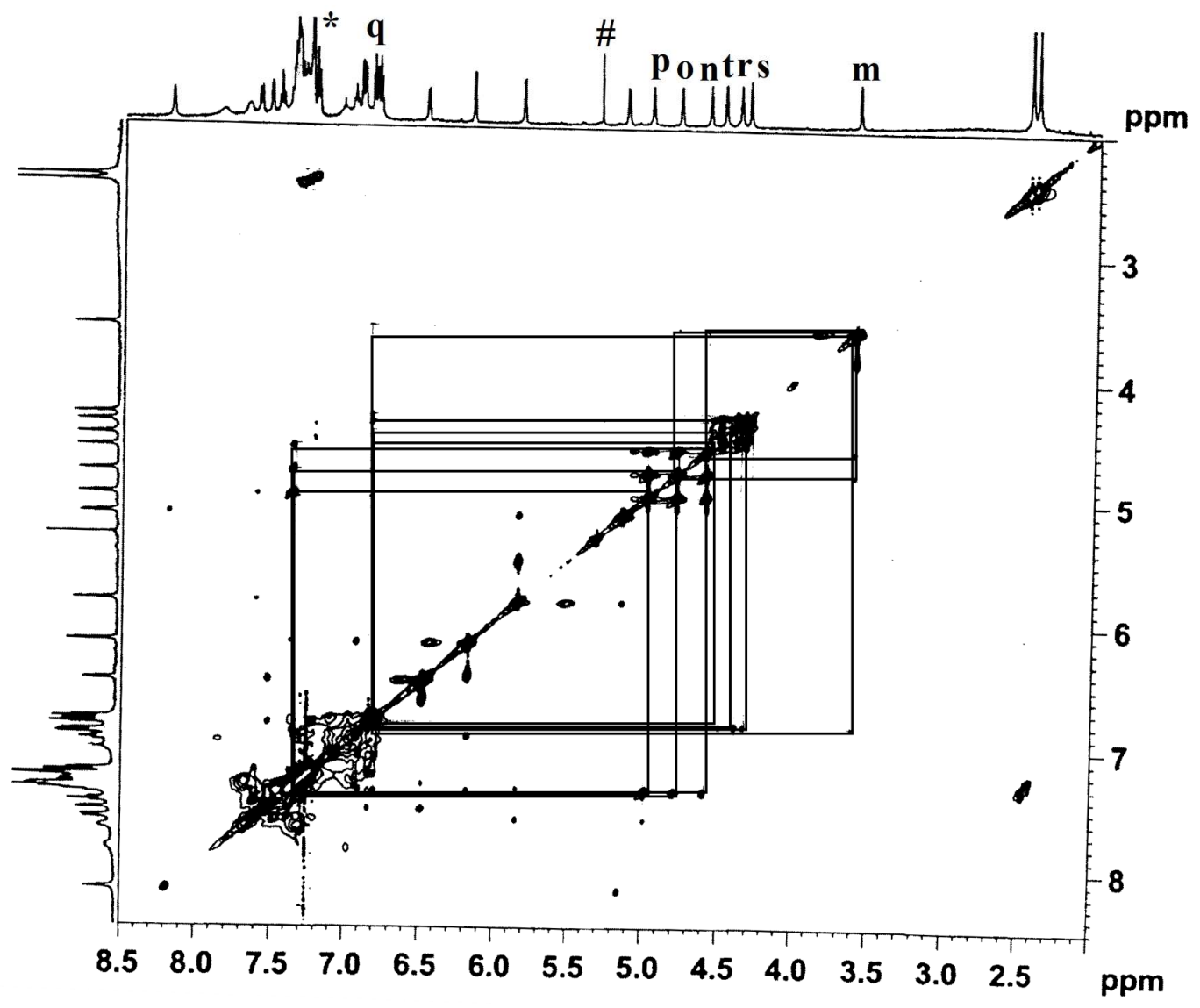

Figure S4: The partial ${ }^{1} \mathrm{H}-{ }^{1} \mathrm{H}$ ROESY NMR spectra of compound 4 showing the cross-peak connectivites between cyclopentadienyl protons (cp1 \& cp2 rings), recorded in $\mathrm{CDCl}_{3}$ at -40 ${ }^{\circ} \mathrm{C}(233 \mathrm{~K})$ (* and \# denote peaks from the residual solvent protons). 


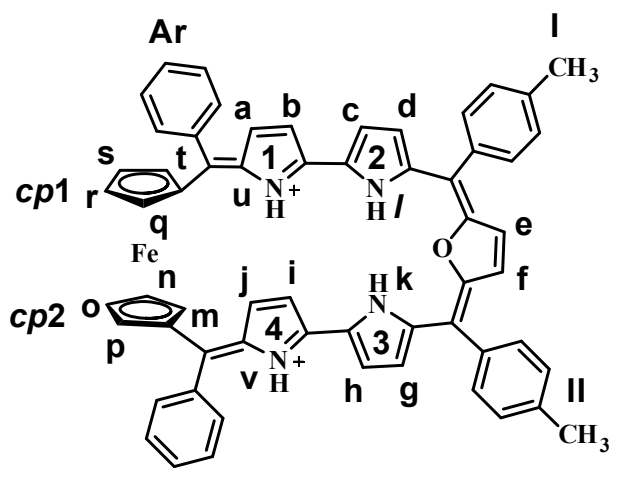

S6

\section{$4.2 \mathrm{H}^{2+}$}

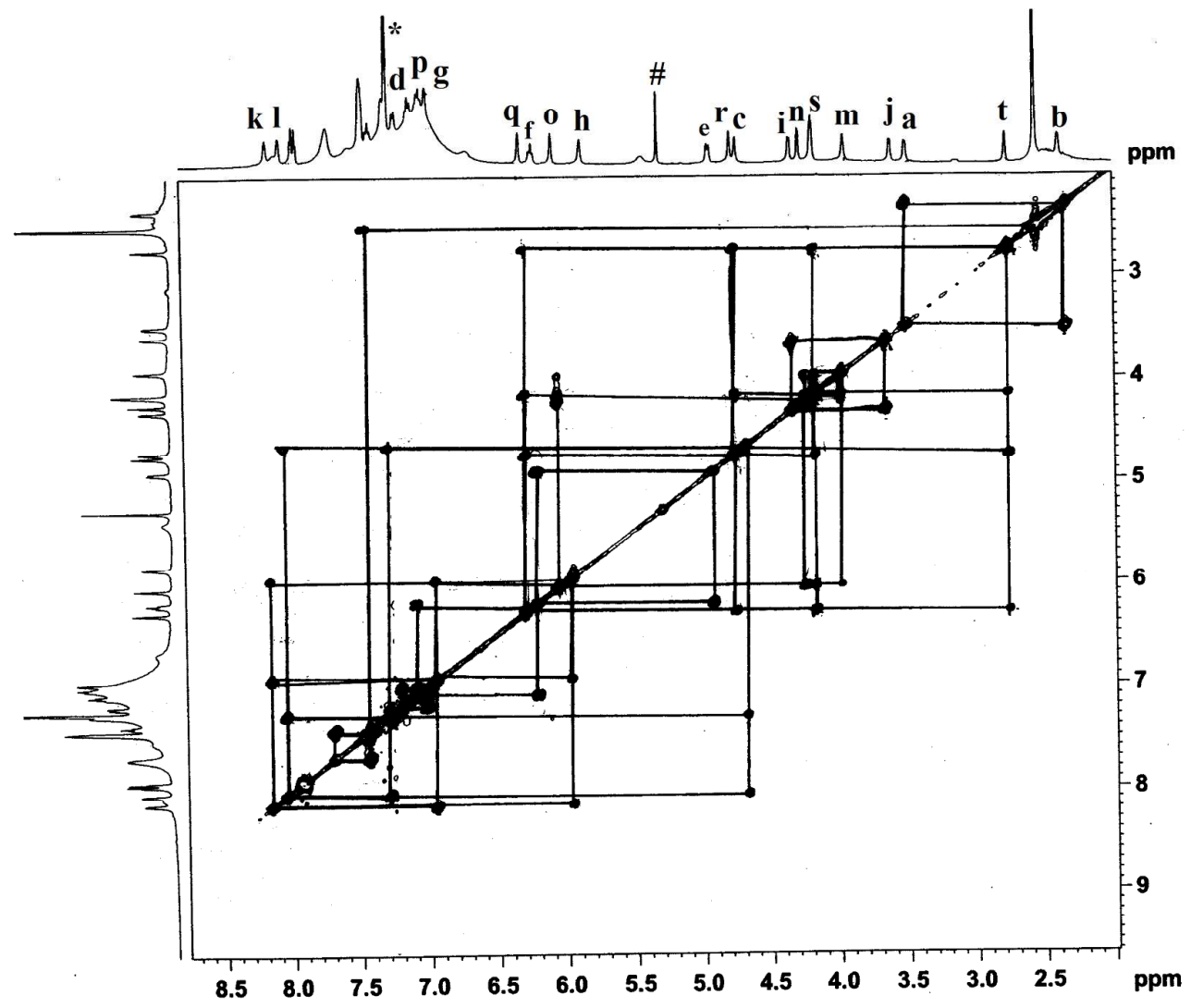

Figure S5: The partial ${ }^{1} \mathrm{H}-{ }^{1} \mathrm{H}$ COSY NMR spectrum of compound $\mathbf{4 . 2} \mathbf{H}^{2+}$ recorded in $\mathrm{CDCl}_{3}$ at room temperature $(*$ and $\#$ denote residual solvent peaks). 


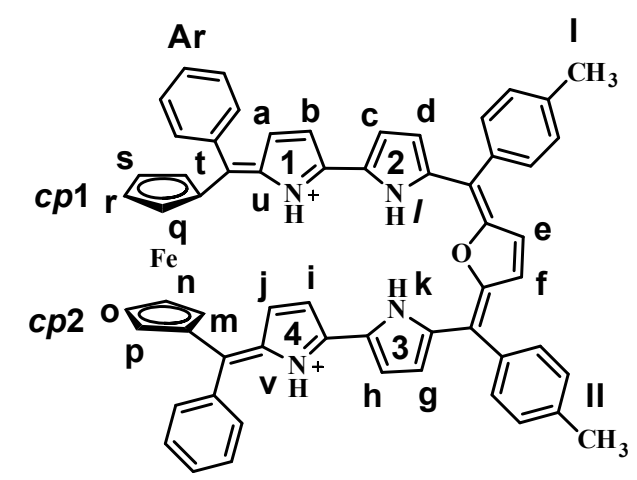

S7

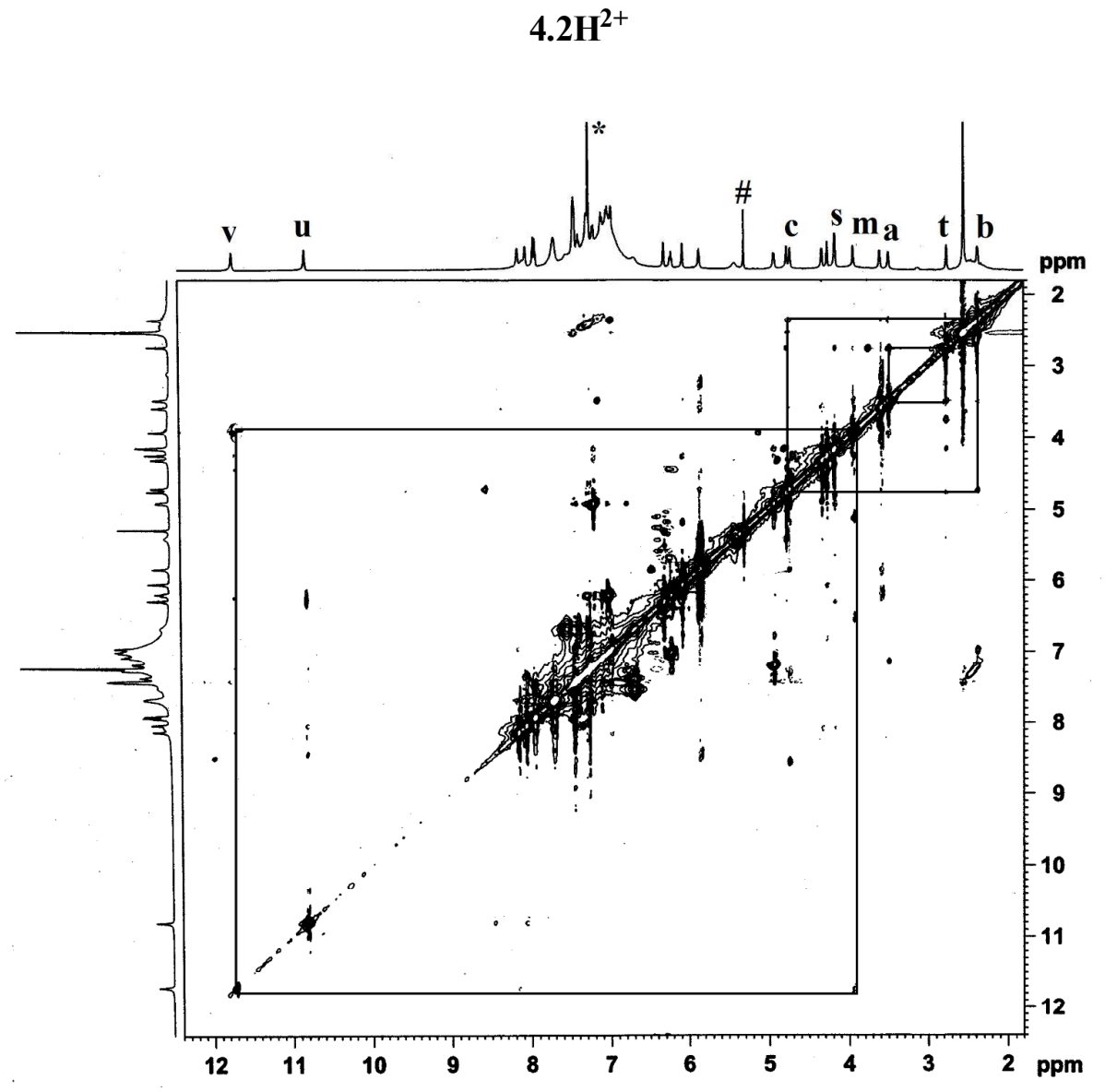

Figure S6: The partial ${ }^{1} \mathrm{H}^{-1} \mathrm{H}$ NOESY NMR spectrum of compound $\mathbf{4 . 2 \mathbf { H } ^ { 2 + }}$ recorded in $\mathrm{CDCl}_{3}$ at room temperature (* and \# denote residual solvent peaks). 


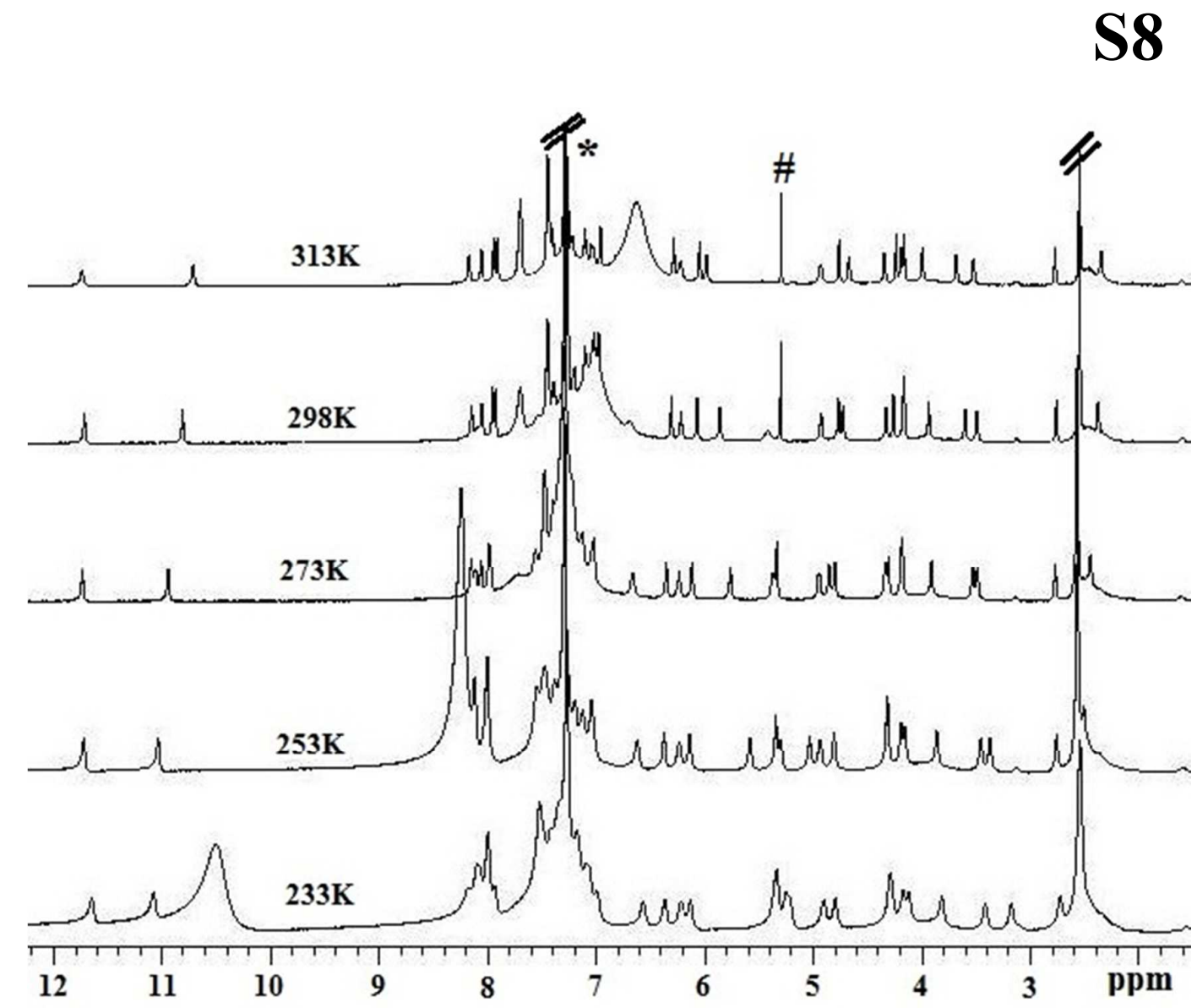

Figure S7: Variable temperature ${ }^{1} \mathrm{H}$ NMR spectra of $\mathbf{4 . 2} \mathbf{H}^{2+}$ recorded in $\mathrm{CDCl}_{3}$. (* and \# denotes residual solvent peaks) 

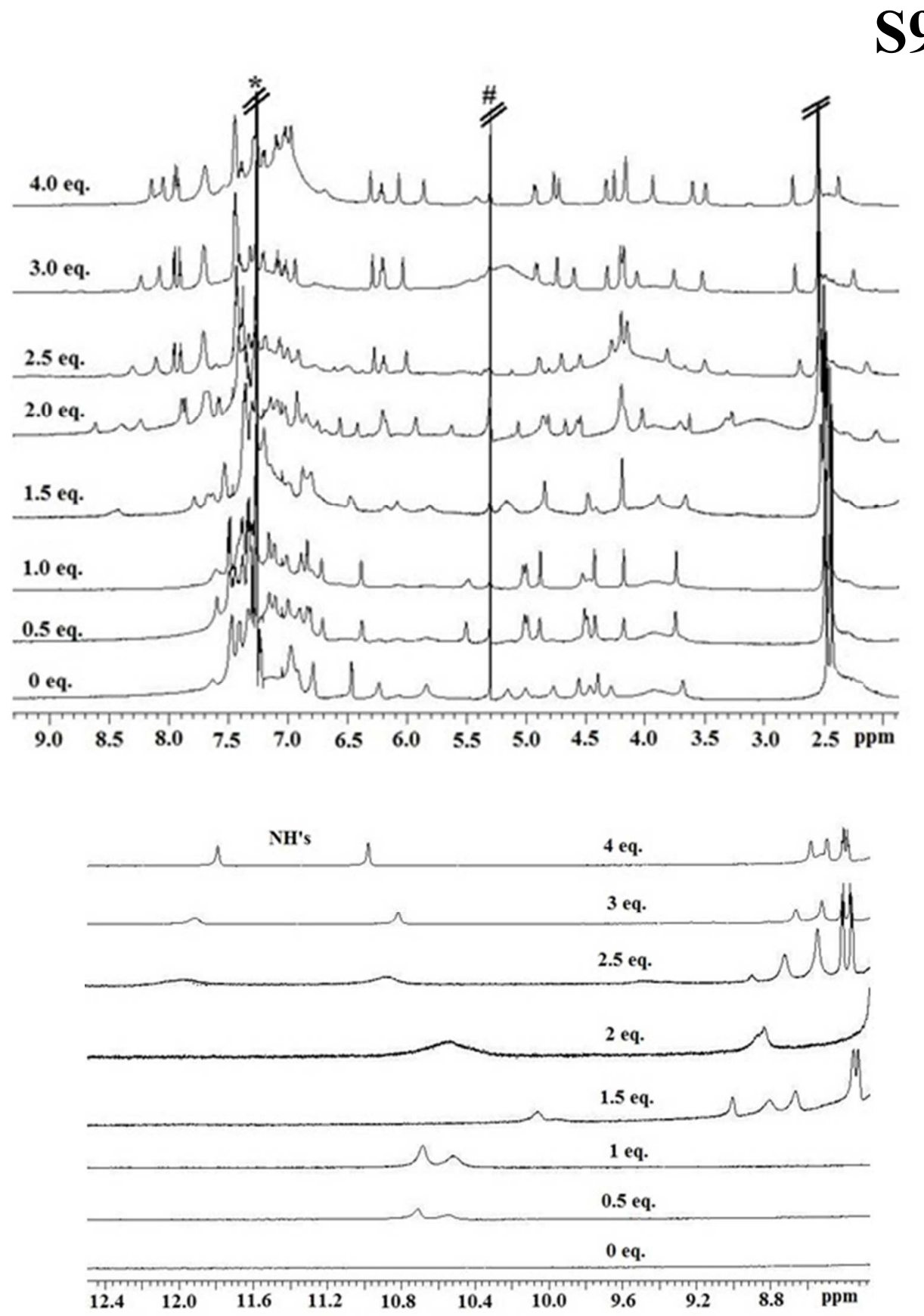

Figure S8: Comparison of ${ }^{1} \mathrm{H}$ NMR spectra of $\mathbf{4 . 2 \mathbf { H } ^ { 2 + }}$ upon titration with TFA (0-4 equiv.) recorded in $\mathrm{CDCl}_{3}$ at room temperature. (* and \# denote residual solvent peaks) 


\section{S10}

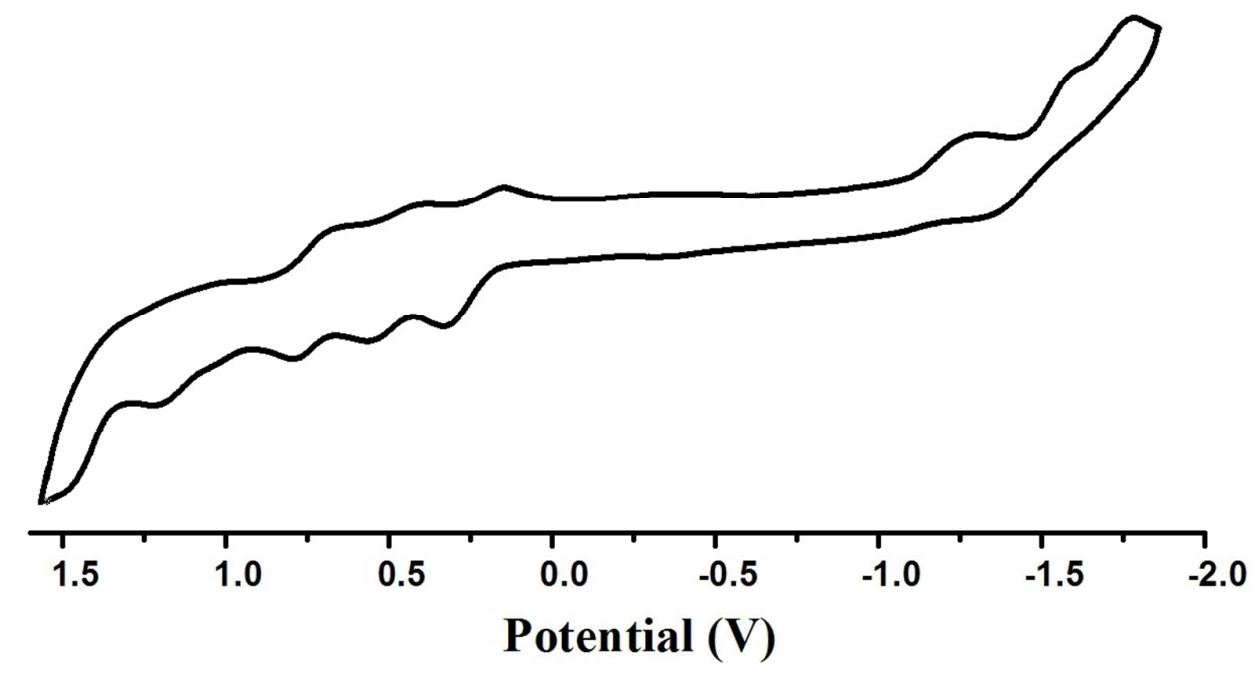

Figure S9: Cyclic voltamogram of compound 4 recorded in $\mathrm{CH}_{2} \mathrm{Cl}_{2}$ containing $0.1 \mathrm{M}$ tetrabutylammonium perchlorate (TBAP) as supporting electrolyte and saturated calomel electrode (SCE) as reference electrode at scan rates of $50 \mathrm{mVs}^{-1}$. 
(a)

S11

\begin{tabular}{|c|c|}
\hline Heterocycles & Dihedral angle (degrees) \\
\hline $\mathrm{N} 1-\mathrm{N} 2$ & 5.91 \\
\hline $\mathrm{N} 2-\mathrm{O}$ & 17.90 \\
\hline $\mathrm{O}-\mathrm{N} 3$ & 16.20 \\
\hline $\mathrm{N} 3-\mathrm{N} 4$ & 165.37 \\
\hline
\end{tabular}

(b)

\begin{tabular}{|c|c|}
\hline Heterocycles & Dihedral angle (degrees) \\
\hline $\mathrm{N} 1-\mathrm{N} 2$ & $6.39^{\circ}$ \\
\hline $\mathrm{N} 2-\mathrm{O}$ & $12.48^{\circ}$ \\
\hline $\mathrm{O}-\mathrm{N} 3$ & $25.51^{\circ}$ \\
\hline $\mathrm{N} 3-\mathrm{N} 4$ & $163.27^{\circ}$ \\
\hline
\end{tabular}

Table S2: The dihedral angles between the heterocycles in the DFT structure of compound (a) 4 and (b) $4.2 \mathrm{H}^{2+}$. 
(a)

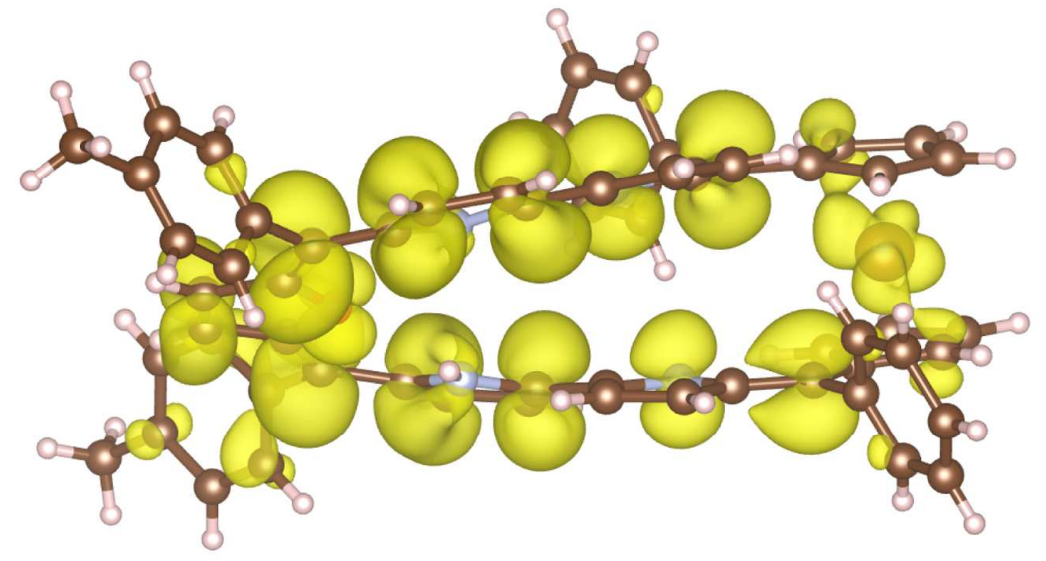

(b)

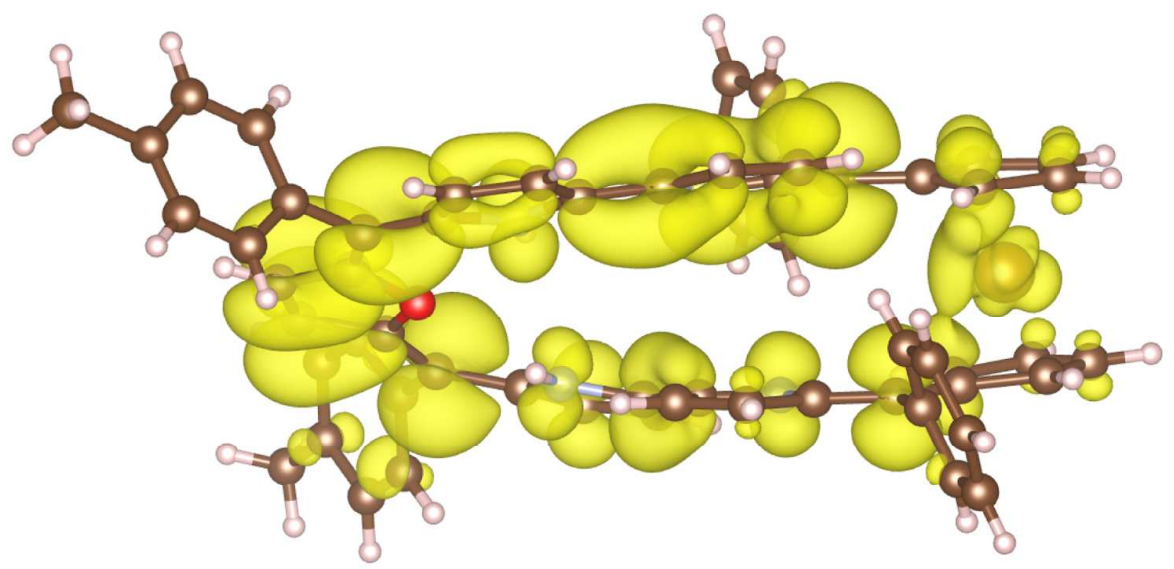

Figure S10: A side view of the (a) HOMO and (b) LUMO state of compound 4 that was obtained from DFT calculations. 
S13

\begin{tabular}{|c|c|}
\hline Substituent group and heterocycle & Dihedral angle (degrees) \\
\hline$c p$ (top) $-\mathrm{N} 1$ & 15.11 \\
\hline Aryl A $-\mathrm{N} 1$ & 74.47 \\
\hline Aryl B $-\mathrm{O}$ & 82.70 \\
\hline Aryl C - O & 53.83 \\
\hline Aryl D - N4 & 69.00 \\
\hline$c p$ (bottom) $-\mathrm{N} 4$ & 2.51 \\
\hline
\end{tabular}

Table S3: The dihedral angles between the meso substituent groups and the $\alpha / \beta$ carbon atoms of heterocyclic rings of compound 4 . 
(a)

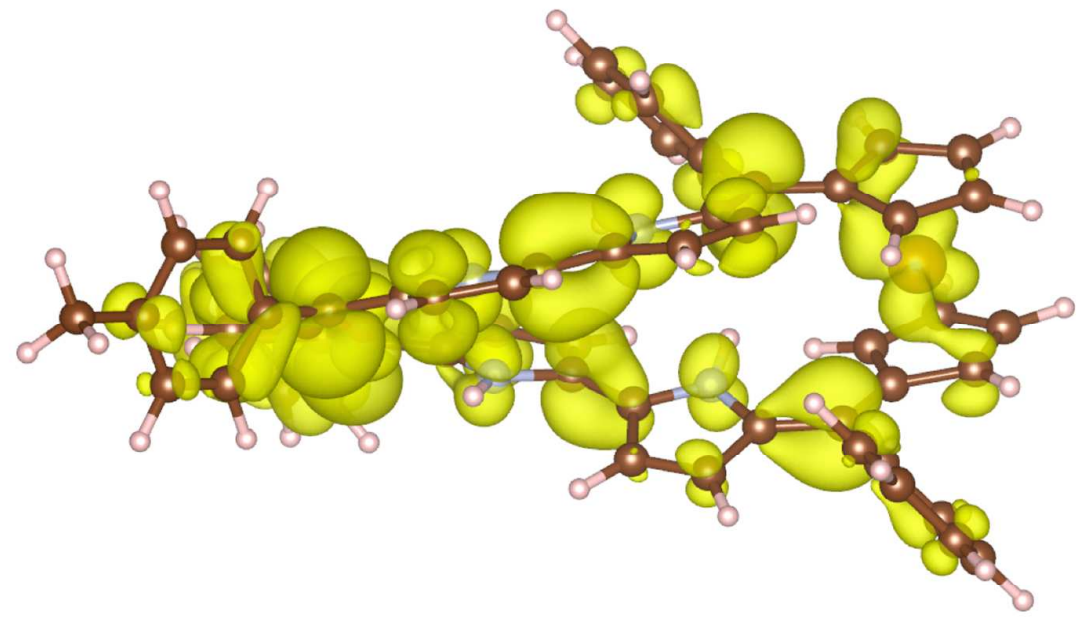

S14

(b)

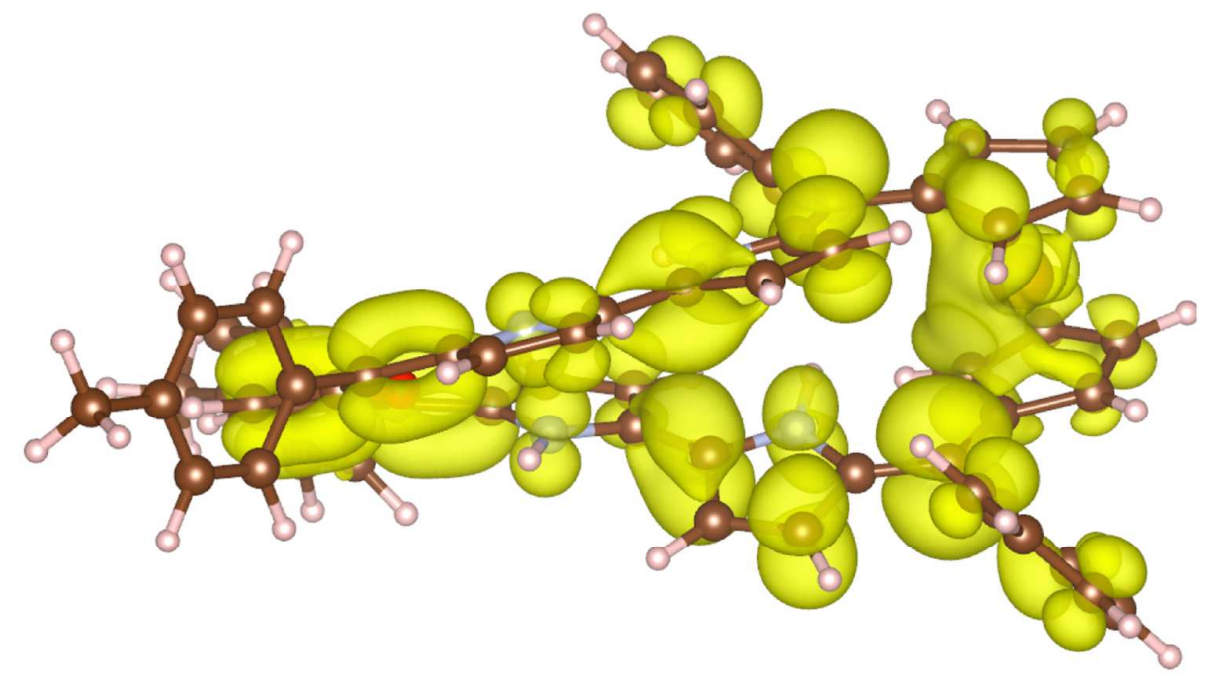

Figure S11: A side view of the (a) HOMO and (b) LUMO state of compound $4.2 \mathbf{H}^{2+}$ that was obtained from DFT calculations. 
S15

\begin{tabular}{|c|c|}
\hline Substituent group and heterocycle & Dihedral angle (degrees) \\
\hline$c p$ (top) $-\mathrm{N} 1$ & $19.44^{\circ}$ \\
\hline Aryl A - N1 & $46.36^{\circ}$ \\
\hline Aryl B - O & $72.32^{\circ}$ \\
\hline Aryl C - O & $50.13^{\circ}$ \\
\hline Aryl D - N4 & $52.98^{\circ}$ \\
\hline$c p$ (bottom) $-\mathrm{N} 4$ & $11.16^{\circ}$ \\
\hline
\end{tabular}

Table S4: The dihedral angles between the meso substituent groups and the $\alpha / \beta$ carbon carbon atoms of heterocyclic rings of compound $4.2 \mathbf{H}^{2+}$. 